\title{
VISUALIZATION OF DATASETS FROM URBAN GEOLOGY STUDIES USING GOOGLE EARTH: THE CASE STUDY OF NAFPLIO, ARGOLIS PREFECTURE.
}

\author{
Zananiri I. ${ }^{1}$, Zervakou A. ${ }^{1}$, Tsombos P. ${ }^{1}$ and Chiotis E. ${ }^{1}$ \\ ${ }^{1}$ Institute of Geology and Mineral Exploration (I.G.M.E.), Olympic Village, 3rd Entrance, 13677 Acharnae, \\ Greece,izanan@igme.gr,zervakou@igme.gr,ptsombos@igme.gr,echiotis@otenet.gr
}

\begin{abstract}
The systematic use of tools provided in Geographic Information Systems in data mapping makes easy the management of the data acquired from urban geology studies. However, the information derived concern not only the scientific society but also the local authorities and the general public. Thus, a simple way of data dissemination had to be adopted. Online tools, such as those pioneered by Google EarthTM $(G E)$, are changing the way in which scientists and the general public interact with geospatial data in a virtual environment. In the past years since its 2005 introduction, GE has introduced numerous applications, in geosciences as well as in many socio-economic disciplines. I.G.M.E., in the framework of CSF 2000 - 2006 (Operational Program "Competitiveness"), implemented the project called "Collection, codification and documentation of geothematic information for urban and suburban areas in Greece. Pilot studies”. Data management and cartographic representation was performed using G.I.S., where a geographic database was created, including all available information for the studied areas: geology, topography, satellite images, geophysical, geochemical, geotechnical, hydrogeological and geoarchaeological data. Critical information from the geodatabase concerning the study area of the city of Nafplio, Argolis Prefecture, were imported in Google Earth and stored as a Keywhole Markup Language Zipped file, rendering a 2-D layer in GE directly, to facilitate dissemination.
\end{abstract}

Key words: Google Earth, GIS database, urban geology, Nafplio.

\section{Introduction}

Sustainable urban planning and development depends on the access to high quality geological data; therefore urban geology has emerged as an important research area worldwide (e.g. Legget, 1969; de Mulder, 1993; Fuchu et al., 1994; Karrow and White, 1998; Nott, 2003). Urban geology studies rely on diverse branches of earth sciences, such as geological mapping, satellite remote sensing, hydrology, engineering geology, geochemistry, geophysics, environmental geology and geoarchaeology, in order to build a three-dimensional model of the character of the land and to explain the geological processes involved in the dynamic equilibrium of the local environment. The acquired geothematic information contributes to the design and implementation of prevention and protection measures against natural hazards, the realization of rational urban planning, the protection and enhancement of the urban and suburban environment and the setting of qualitative and quantitative targets for environmental goods. They constitute a constant source of information for the compilation 


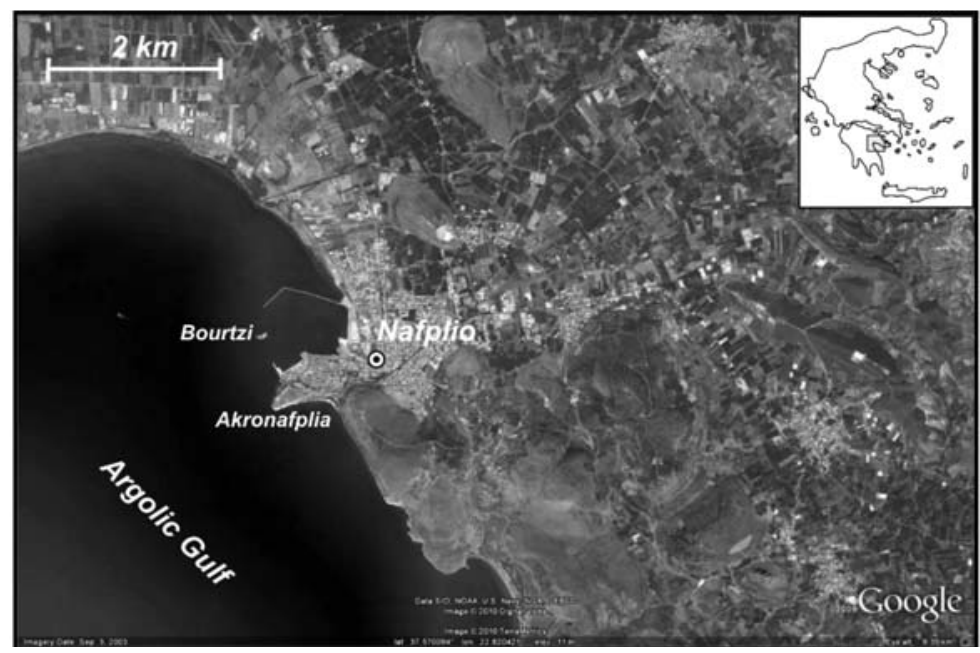

Fig. 1: Satellite image from Google Earth showing the location of the city of Nafplio and main topographic features of the broader area.

of studies, as well as reference point for possible future changes, ensuring the spatial and geological coherency of the entire data set (maps, borehole logs, geophysical measurements, etc). Furthermore, the interoperability of data banks at urban and national levels is a stake of prime importance for all providers of referenced geological data.

Geographic Information Systems (GIS) is a powerful tool for many aspects of geospatial analyses (Longley et al., 2001), but while used routinely to map data and solve complex problems, its adoption in data sharing has been lagging. Part of the problem is that desktop GIS software is commercial and complex in use and the required geospatial data are in most cases inaccessible for non-professional users. Open source solutions for Web mapping, such as the UMN MapServer (MapServer, 2009) or Deegree (Deegree, 2007) are often available for free, but require knowledge of digital maps, encoding and transfer protocols. The recent development of Google Earth (GE; Google Inc., 2009), a free web-based geographical information service that provides satellite imagery and three-dimensional (3D) data depicting the entire planet, has changed the way in which scientists and the general public interact with geospatial data in a virtual environment.

In this paper we demonstrate how geospatial data can be easily displayed and communicated by combining GE and GIS, using data from an urban geology study, carried out by the Institute of Geology and Mineral Exploration (I.G.M.E.) of Greece.

\section{The case study of Nafplio}

The first systematic recording, codification and documentation of "Urban geology" geothematic information in Greece was implemented by the I.G.M.E. with the participation of 70 specialized scientists and 30 technical employees, in the frame of the project "Collection, codification and documentation of geothematic information for urban and suburban areas in Greece - pilot applications" (Operational Program "Competitiveness", Community Support Framework 2000-2006) (Tsombos and Zervakou, 2010). Subproject 3, called "Integrated geological, geotechnical, hydrogeological, geochemical, geophysical and marine studies of the urban and suburban pilot area of Nafplio, Argolis prefecture" (Zervakou et al., 2007), focused in the broader area of Nafplio (Fig. 1), in north eastern Peloponnese. 

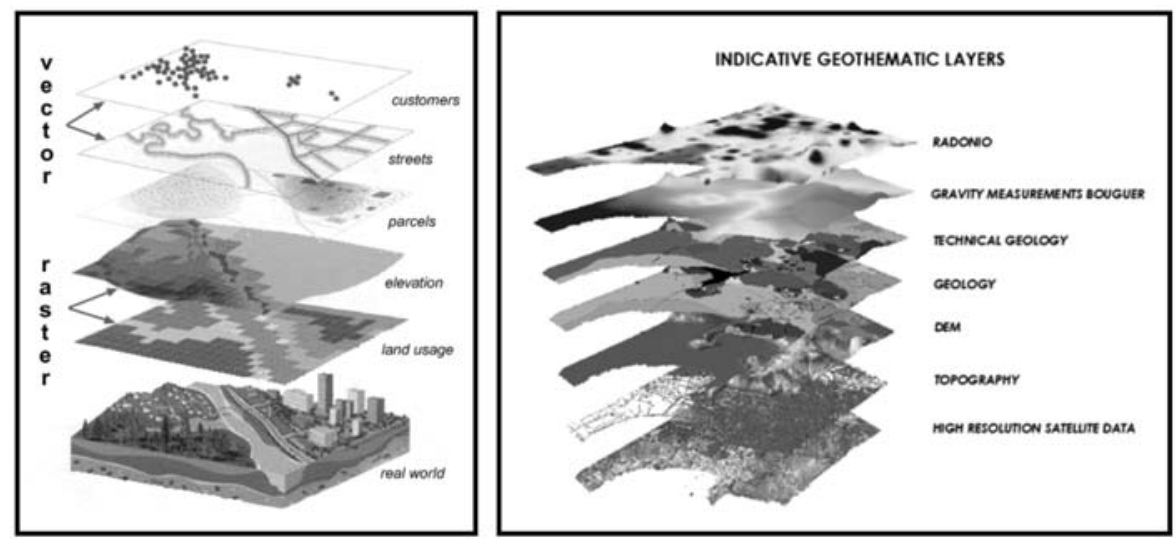

Fig. 2: The concept of geothematic layers (ESRI) in a general example for urban development (left) and the case of Nafplio from the urban geology project of IGME (right).

During the elaboration of this project "in situ" studies and measurements took place; all geoscience information derived from various sources such as borehole logs, geological mapping, geotechnical, geochemical, geophysical research and measurements, hydrological reports and digital elevation models were compiled, stored and processed in specially designed georeferenced databases in GIS environment.

\subsection{General information of the study area}

Nafplio (146 km southwest of Athens) is a seaport city that has been expanded up to the hillsides near the north end of the Argolic Gulf (Argolikos Bay). Most of the old city is on a peninsula jutting into the gulf. This peninsula forms a naturally protected bay that is enhanced by the addition of man-made moles.

The city was the First capital of the liberated, from the Turks, Greece from 1829 to 1834. Its buildings, renowned castles and generally the whole layout of the city makes Nafplio an important tourist centre. The fortress complex of Nafplio is extensive and imposing. The oldest fortress of all is Akronafplia, in the homonymous peninsula. On the opposite rocky hill rises the famous Palamidi. Bourtzi is found in front of the harbour, in the shallow waters. All three castles are remarkable not only for their archaeological importance but also for their incredible location.

Nafplio city is connected with the national road Corinth - Tripoli through main provincial transportation network via Argos (SW of Nafplio). Also there is now a railway station with daily trains from/to Corinth and Athens and there is a connection with Ermioni, Porto Heli, Tolo, and the Argosaronic Gulf Islands by flying dolphins or boats from Piraeus. As a result, Nafplio is a well-connected city with the mainland Peloponnese and the near ports.

\section{Applied methodology}

\subsection{GIS applications}

GIS are used by a heterogeneous group of individuals and organizations for an incredibly wide variety of applications. A Geographic Information System is best described as an integrated collection of hardware, software, data and computer users, which operates in an institutional context. The key features that differentiate GIS from other information systems are the general focus on spatial entities and relationship, together with specific attention to spatial analytical and modelling operations. 

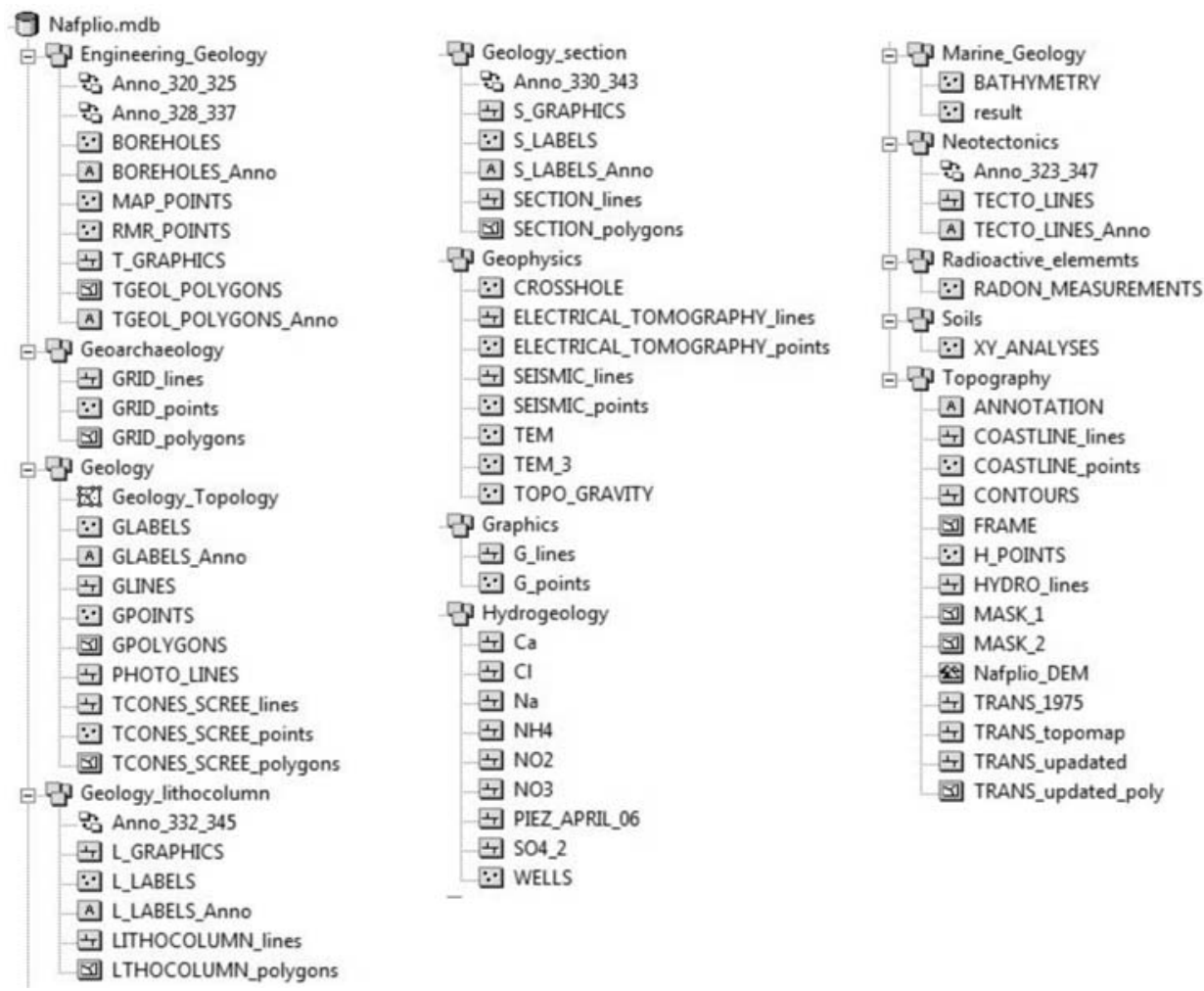

Fig. 3: Nafplio Urban geology geodatabase contents.

In a technical sense, it is the ability to organize and integrate apparently disparate data sets together which makes GIS so powerful (Maguire, 1991).

The spatial searching and overlay operations are a key functional feature of GIS (Maguire, 1991). A more comprehensive and easy way to define GIS is the one that looks at the disposition, in layers (Fig. 2), of its data sets.

Geographic information systems have emerged in the last decade as an essential tool for urban and resource planning and management. Their capacity to store, retrieve, analyse, model and map large areas with huge volumes of spatial data has led to an extraordinary proliferation of applications. Geographic information systems are now used for land use planning, utilities management, ecosystems modelling, landscape assessment and planning, transportation and infrastructure planning, market analysis, visual impact analysis, facilities management, tax assessment, real estate analysis and many other applications.

Within a Geographic Information System a spatial database or so called "Geodatabase" is a crucial component that can be used to store, manipulate and process such complex data derived from urban survey and study. Geodatabases enable efficient state management and archiving of geodata. Actually, the geodatabase is the core geographic information model to organize GIS data into thematic layers and spatial representations. It supports both vector and raster data, while entities are represented as objects with properties, behaviour, and relationships. 
For the specific urban geology project of IGME a geodatabase called "Nafplion" (Fig. 3) was built in GIS Environment (software ArcGIS 9x, ArcInfo version, ESRI). The used format for editing and data management was ArcGIS Geodatabase, a native data structure for ArcGIS software. It is a collection of geographic datasets of various types held in a common file system folder, a Microsoft Access database, or a multi-user relational database, such as Oracle, Microsoft SQL Server, or IBM DB2.

All geoinformation is compiled in feature classes and grouped in the following thematically organized feature datasets (a detailed description of dataset contents is given by Zervakou \& Tsombos, 2010):

- Feature dataset Topography

- Feature dataset Geology

- Feature dataset Engineering Geology

- Feature dataset Neotectonics

- Feature dataset Marine Geology:

- Feature dataset Hydrogeology

- Feature dataset Geophysics

- Feature dataset Soils

- Feature dataset Radioactive elements

- Feature dataset Geoarchaeology

\subsection{Web-based application}

Access to spatial data as well as advanced mapping and spatial analysis over the Internet is becoming more common (e.g. Beaudette and O'Green, 2009; Montesano et al., 2009). Recent attention has focused on developing GIS functionality in the Internet, Worldwide Web and private intranets, termed as WebGIS.

WebGIS holds the potential to make distributed geographic information available to a very large worldwide audience. In order to access the spatial information, the user needs only to have a Web browser and access to the Internet. This way, internet users are able to access GIS applications from their browsers without purchasing proprietary GIS software.

Web 2.0 applications such as Google Maps, Yahoo Maps, or Microsoft Live Maps provide free access to easy-to-use functionality as well as high-quality map data. With the success of Google Earth (2007) and Microsoft Virtual Earth (2007), the broader community has found an interest in visualising scenarios, city-centres and entire maps interactively in 3D (e.g. Pearce et al., 2007; Conroy et al., 2008).

More specifically, Google Earth combines satellite imagery, geographic data and Google's search capabilities to create a virtual globe application that you can download to your desktop to access online spatial data. GE is a virtual globe, currently freely available for personal use on PC running on Windows, Macintosh and Linux operating system. For commercial and professional use many, affordable, solutions are available. The original project was developed by Keyhole Inc. (2001), which was bought by Google in 2004.

Data organized in layers can be exported to the Keyhole Mark-up Language (KML/KMZ) native to GE, transmitted to colleagues, members of the local authorities or even the general public as an email attachment, and then simply "dragged and dropped" by the recipient onto their own desktop GE display, where the map layers appear "draped" over the GE landscape. The recipient has access to all the graphics and attributes of each map layer that has been exported from GIS as well as to all GE tools, e.g. ability to adjust map layer transparencies, labelling, longitude/latitude (or UTM determinations), 


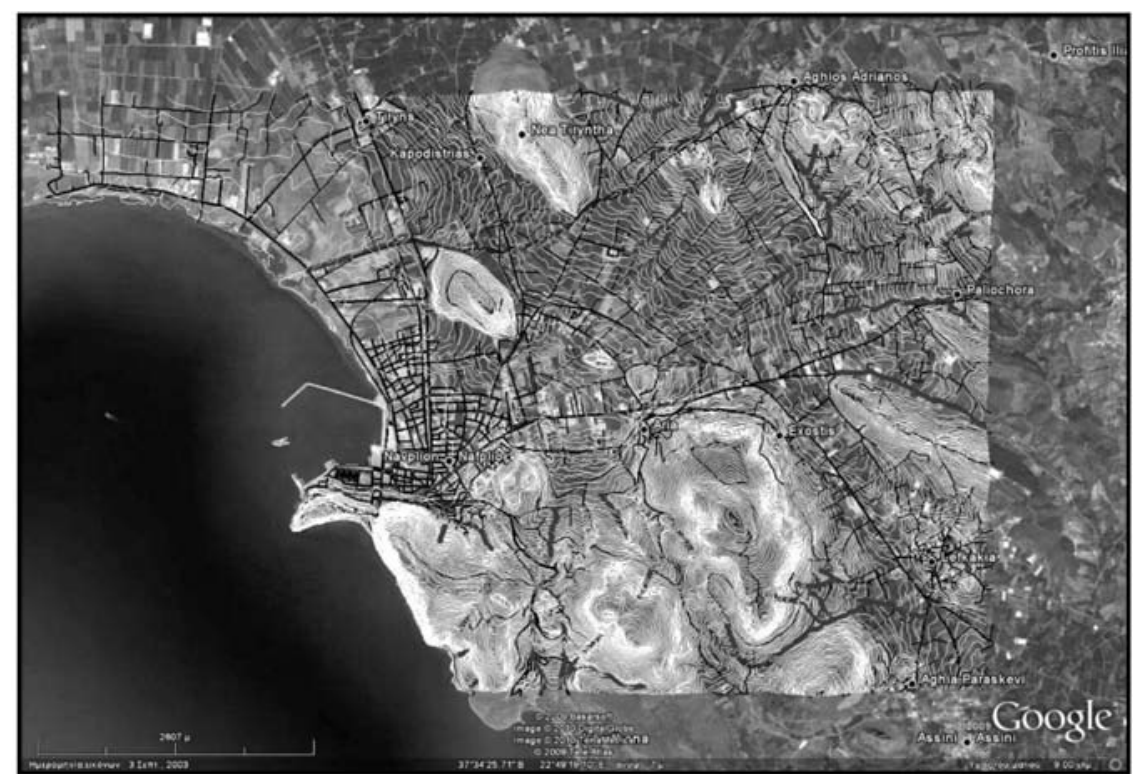

Fig. 4: Google Earth representation of topographic linear spatial features (contours, hydrological network, transportation network) from the broader area of Nafplio.

spatial measurements, and "tilting" of landscapes for enhanced 3D views. These tools are often sufficient to allow the non-GIS user to obtain specific information of interest from the data.

\section{Examples of dataset visualization in the study area}

One of the challenges met during the elaboration of the urban geology project was the dissemination of the results to users of different access levels. In this paper, we present how GIS data derived from the "Urban geology" project of IGME can be freely and easily transmitted to anyone with Internet access and familiarity with Google Earth. Thematic layers, created in ArcGIS, were converted from EGSA' 87 (Greek Geodetic Reference System of 1987) to WGS84 Geographic Coordinate System to ensure compatibility with GE and then exported to a KMZ data file.

\subsection{Topography}

Detailed topography is a key feature for every study concerning spatial information. Thus, all available topographic data for the broader Nafplio area were digitized and imported in the "Nafplio" database. A graphic representation of the most important topographic linear features is given in Figure 4.

\subsection{Geology}

A detailed geological mapping in a 1:5.000 scale was performed by Photiades (2008). According to this survey the broader Nafplio area is covered by alluvial deposits, mainly lagoonal, overlying flysch and limestone formations (Fig. 5).

\subsection{Neotectonics}

According to a thorough neotectonic study, carried out by Galanakis and Georgiou (2008), the 


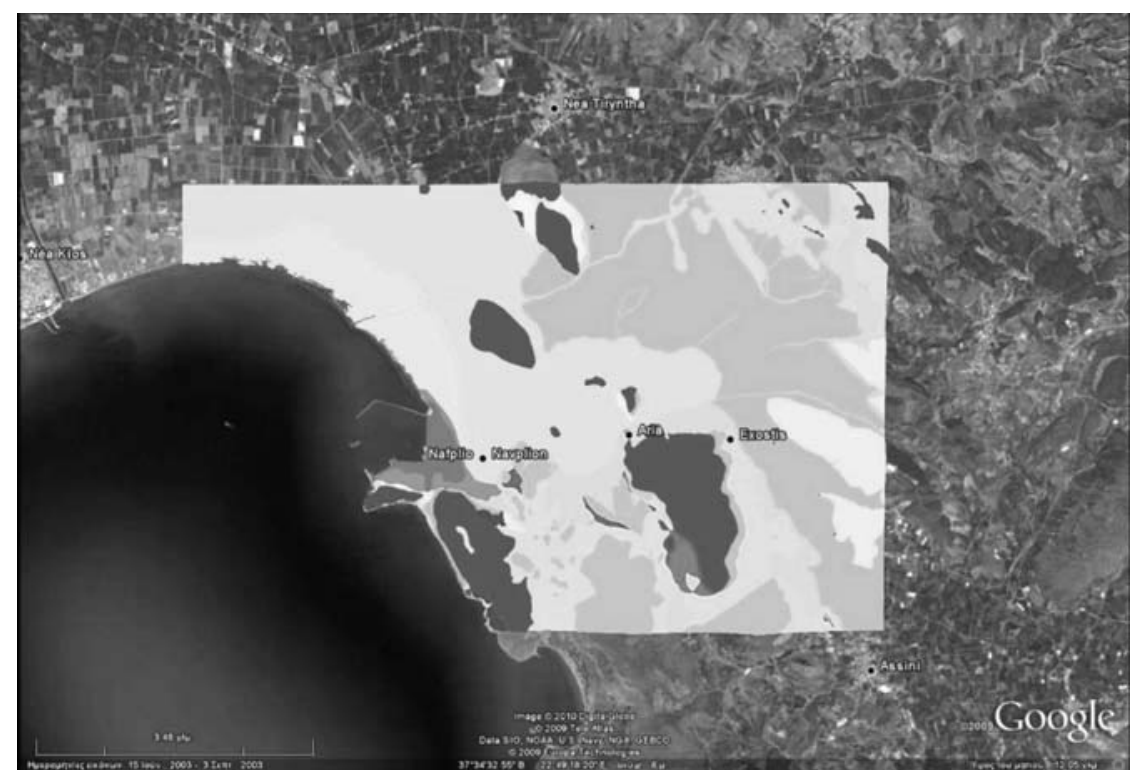

Fig. 5: Google Earth representation of geological formations from the broader area of Nafplio (Photiades, 2008).

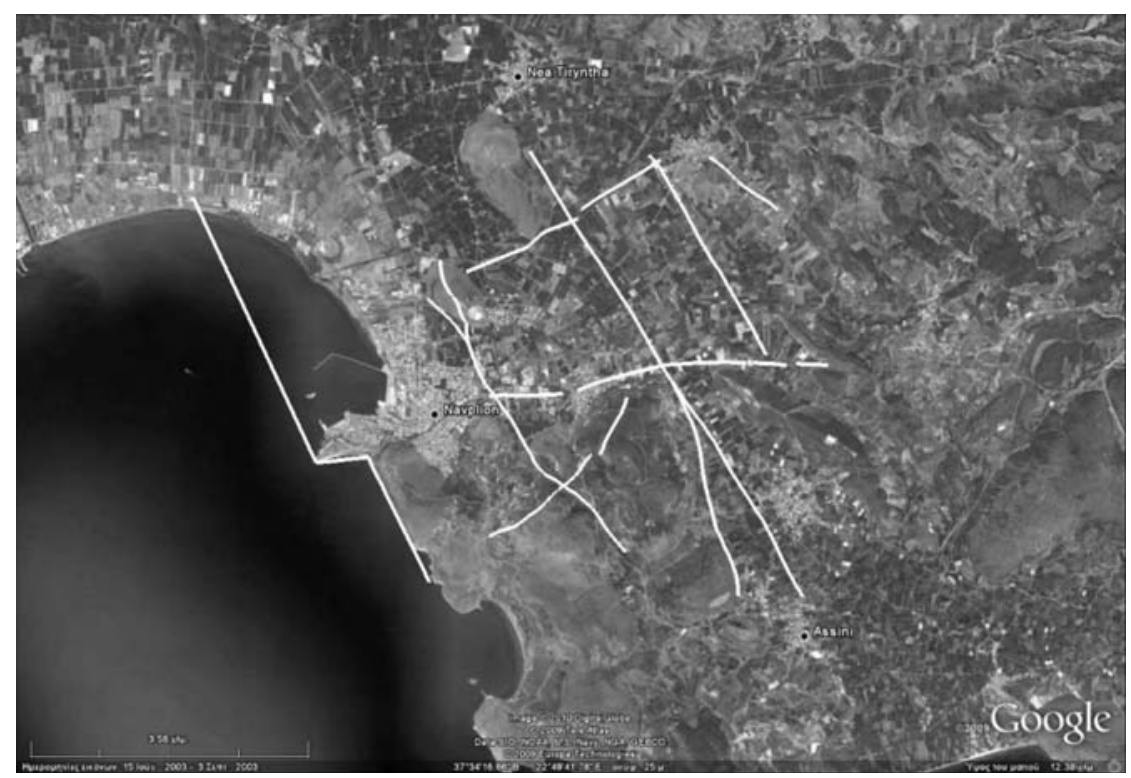

Fig. 6: Google Earth representation of neotectonic linear features from the broader area of Nafplio (Galanakis and Georgiou, 2008).

broader area of Nafplio is characterized by the existence of active and potentially active faults mainly found in the boundaries of basins (Fig. 6). 


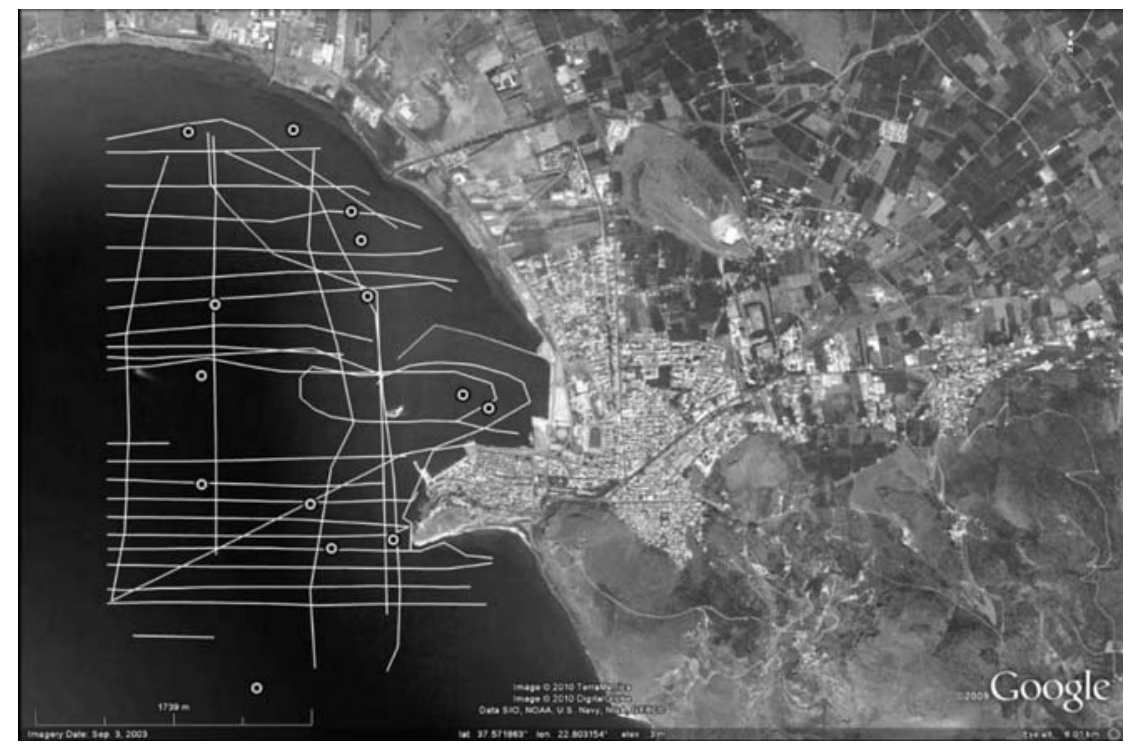

Fig. 7: Google Earth representation showing the location of seismic-reflection profiles and surface samples collected from the Argolic Gulf (Andrinopoulos et al., 2008).

\subsection{Marine Geology}

In the framework of the urban geology project, marine geology research was carried out in the Gulf surrounding the city of Nafplio (Andrinopoulos et al., 2008). The survey included 26 high-resolution seismic-reflection profiles and the collection of 14 sea-bottom surface samples (Fig. 7).

\subsection{Geoarchaeology}

A significant characteristic of urban and suburban areas, that has to be taken into account during urban development, is the presence of archaeological remains. Thus, during the elaboration of the urban geology project of I.G.M.E., an approach to the study of archaeological issues was attempted, using the methods and concepts of the earth sciences (Zananiri et al., 2010). An example is presented in Figure 8, where the archaeological protection zones of the broader area of Nafplio were mapped in detail.

\section{Conclusions}

In this paper we dealt with the crucial issue of data dissemination from urban geology studies to various recipients. We demonstrated how map layers, originally created in ArcGIS, can be shared with users having no experience with or access to GIS by sending an email attachment. All that is required is access to the Web and Google Earth, a powerful and freely downloadable geographic visualization tool. This opens up enormous possibilities for the free and easy dissemination of geospatial information in a visually meaningful and stimulating way to colleagues, local authorities and the interested general public around the world. Furthermore, this well-organized and easily accessible dataset can constitute a valuable tool in the hands of public authorities towards decision making and control, e.g. of building activities outside the defined urban development areas. 


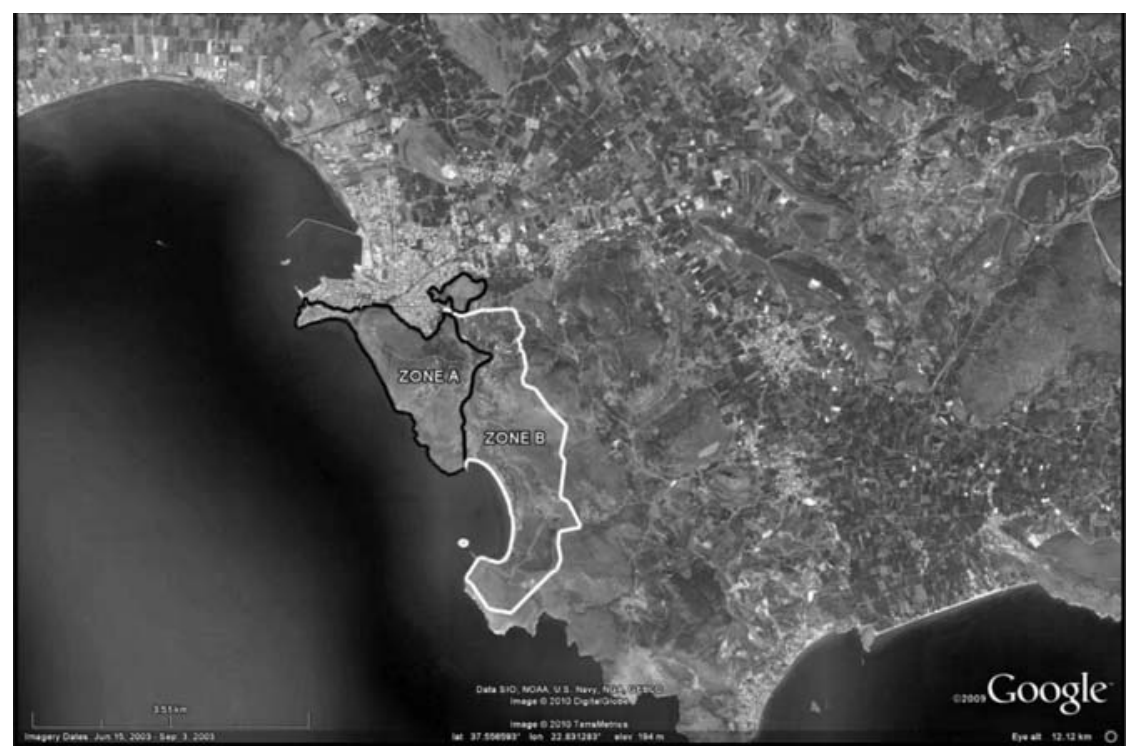

Fig. 8: Google earth representation of archaeological protection zones for the Nafplio area. Zone A corresponds to totally protected areas where no construction is allowed; Zone B encloses partially protected areas where conditional construction is allowed.

Through the Google Earth platform the derivative maps (geological, geotechnical, geochemical, geophysical etc.) and other digital data such as sampling points, elevation models, 2D - 3D digital surfaces are available and accessible to all, public or private sector or even general public, managing issues concerning the protection and enhancement of the urban and suburban environment.

A KMZ file with the geospatial data from the pilot area of Nafplio, for level C users (general public), can be requested via e-mail from the authors or downloaded from the IGME website: http://www.igme.gr. It is intended that the results from subsequent studies will be incorporated into the Nafplio "urban geology" database, and consequently the GE file, keeping users up-to-date. Moreover, following the example of Compieta et al. (2007), we plan to create a Google Earth-based tool for data mining and spatial analysis. This application will incorporate widgets designed to select the information to deal with, which will be rendered in 3D over a map and other layers provided by GE.

\section{Acknowledgements}

This work was funded by the Community Support Framework 2000 - 2006 (Operational Program "Competitiveness"). We thank all colleagues who participated in this multidisciplinary project, the first integrated urban geology study in Greece.

\section{References}

Andrinopoulos, A., Zacharaki, P., Zimianitis, E., Maroulakis, S., Mitropoulos, D. and Efthimiou, G., 2008. Marine geology research in the northern Argolic gulf - Nafplio area, Argolis prefecture. Tecnical Report I.G.M.E., Athens, Greece.

Beaudette, D.E. and O'Geen, A.T., 2009. Soil-Web: An online soil survey for California, Arizona, and Nevada. Computers \& Geosciences, 35, 2119-2128. 
Compieta, P., Di Martino, S., Bertolotto, M., Ferrucci, F. and Kechadi, T., 2007. Exploratory spatio-temporal data mining and visualization. Journal of Visual Languages \& Computing, 18, 255-279.

Conroy, G.C., Anemone, R.L., Van Regenmorter, J. and Addison, A., 2008. Google Earth, GIS, and the Great Divide: A new and simple method for sharing paleontological data. Journal of Human Evolution, $55,751-755$.

Deegree, 2007 (accessed 02/12/2009). Deegree - Free software for spatial data infrastructures. URL: http://www.deegree.org

Fuchu, D., Yuhai, L. and Sijing, W., 1994. Urban geology: a case study of Tongchuan city, Shaanxi Province, China. Engineering Geology, 38 (1-2), 165-175.

Galanakis, D. and Georgiou, Ch., 2008. Neotectonic study at the urban and suburban area of Nafplio city (pilot application). Technical report, I.G.M.E.,, Athens, Greece.

Google Inc., 2009 (accessed 15/06/2009). Google Earth: A 3D interface to the planet. URL: http://earth.google.com/

Karrow, P.F. and White, O.L., 1998. Urban Geology of Canadian cities. Geological Association of Canada, special paper 42 , p.p. 500 , Canada.

Legget, R.F., 1969. Urban Geology. Canadian Building Digest, CBD - 113, National Research Council Canada, URL: http://irc.web-t.cisti.nrc.ca/cbd/cbd113e.html

Longley, P.A., Goodchild, M.F., Maguire, D.J. and Rhind, D.W., 2001. Geographic Information Systems and Science. John Wiley \& Sons, $472 \mathrm{pp}$.

Maguire, D.J., 1991. An overview and definition of GIS. In: D.J. Maguire, M.F. Goodchild and D.W. Rhind (eds), Geographical Information Systems Principles and Applications. Longman Scientific and Technical, John Wiley and Sons, Inc., New York, 9-20.

MapServer, 2009 (accessed 02/12/2009). Mapserver - Open source development environment for building spatially enabled internet applications. URL: http://mapserver.gis.umn.edu/

Montesano, P.M., Nelson, R., Sun, G., Margolis, H., Kerber, A. and Ranson, K.J., 2009. MODIS tree cover validation for the circumpolar taiga-tundra transition zone. Remote Sensing of Environment, $113,2130-2141$.

De Mulder, E.F.J., 1993. Urban geology in Europe: overview. Quaternary International, 20, 5-11.

Nott, J.F., 2003. The urban geology of Darwin, Australia. Quaternary International, 103, 83-90.

Pearce, J.M., Johnson, S.J. and Grant, G.B., 2007. 3D-mapping optimization of embodied energy of transportation. Resources, Conservation \& Recycling, 51, 435-453.

Photiadis A., 2008. Geological study of the urban and the wider Nafplio area. Argolida Prefecture. Technical Report I.G.M.E., Athens, Greece.

Tsombos, P.I. and Zervakou, A.D., 2010. The "Urban Geology" project of IGME. Bulletin of the Geological Society of Greece, Proc. of the $12^{\text {th }}$ International Congress (this volume).

Zananiri, I., Chiotis, E., Tsombos, P., Hademenos, V. and Zervakou, A., 2010. Geoarchaeological research in urban and suburban areas of the Argolis Prefecture. Bulletin of the Geological Society of Greece, Proceedings of the $12^{\text {th }}$ International Congress (this volume).

Zervakou, A.D., Tsombos, P.I. and Nikolakopoulos, K.G., 2007. Urban Geology: Documentation of geothematic information for urban areas in Greece, the case of Nafplio Greece. $14^{\text {th }}$ International Symposium on Remote Sensing of the International Society for Optical Engineering, Florence, Italy, Vol. 6749, 67491G1-12.

Zervakou, A.D. and Tsombos, P.I., 2010. GIS in Urban Geology. The case of Nafplio city, Greece. Bulletin of the Geological Society of Greece, Proceedings of the $12^{\text {th }}$ International Congress (this volume). 